\title{
A randomised placebo controlled trial of anakinra for treating pustular psoriasis: statistical analysis plan for stage two of the APRICOT trial
}

Suzie $\mathrm{Cro}^{1 *}$ (D), Prakash Patel ${ }^{2}$, Jonathan Barker ${ }^{3}$, David A. Burden ${ }^{4}$, Christopher E. M. Griffiths ${ }^{5}$, Helen J. Lachmann ${ }^{6}$, Nick J. Reynolds', Richard B. Warren ${ }^{8}$, Francesca Capon ${ }^{9}$, Catherine Smith ${ }^{2,3}$ and Victoria Cornelius ${ }^{1}$

\begin{abstract}
Background: Current treatment options for Palmoplantar Pustulosis (PPP), a debilitating chronic skin disease which affects the hands and feet, are limited. The Anakinra for Pustular psoriasis: Response in a Controlled Trial (APRICOT) aims to determine the efficacy of anakinra in the treatment of PPP. This article describes the statistical analysis plan for the final analysis of this two-staged trial, which was determined prior to unblinding and database lock. This is an update to the published protocol and stage one analysis plan.
\end{abstract}

Methods: APRICOT is a randomised, double-blind, placebo-controlled trial of anakinra versus placebo, with two stages and an adaptive element. Stage one compared treatment arms to ensure proof-of-concept and determined the primary outcome for stage two of the trial. The primary outcome was selected to be the change in Palmoplantar Pustulosis Psoriasis Area and Severity Index (PPPASI) at 8 weeks. Secondary outcomes include other investigator-assessed efficacy measures of disease severity, participant-reported measures of efficacy and safety measures. This manuscript describes in detail the outcomes, sample size, general analysis principles, the prespecified statistical analysis plan for each of the outcomes, the handling of missing outcome data and the planned sensitivity and supplementary analyses for the second stage of the APRICOT trial.

Discussion: This statistical analysis plan was developed in compliance with international trial guidelines and is published to increase transparency of the trial analysis. The results of the trial analysis will indicate whether anakinra has a role in the treatment of PPP.

Trial registration: ISCRTN, ISCRTN13127147. Registered on 1 August 2016. EudraCT Number 2015-003600-23. Registered on 1 April 2016.

Keywords: Psoriasis, Palmoplantar pustulosis, Randomised controlled trial, Anakinra, Adaptive trial, Statistical analysis plan

\footnotetext{
* Correspondence: s.cro@imperial.ac.uk

${ }^{1}$ Imperial Clinical Trials Unit, Imperial College London, W12 7RH, London, UK

Full list of author information is available at the end of the article
}

(c) The Author(s). 2020 Open Access This article is distributed under the terms of the Creative Commons Attribution 4.0 International License (http://creativecommons.org/licenses/by/4.0/), which permits unrestricted use, distribution, and reproduction in any medium, provided you give appropriate credit to the original author(s) and the source, provide a link to the Creative Commons license, and indicate if changes were made. The Creative Commons Public Domain Dedication waiver (http://creativecommons.org/publicdomain/zero/1.0/) applies to the data made available in this article, unless otherwise stated. 


\section{Background}

Palmoplantar pustulosis (PPP) is a debilitating chronic skin disease which affects the hands and feet. PPP produces intensely inflamed skin, covered with pustules. Unfortunately treatment options are currently limited [1]. Recent evidence suggests that interleukin1 (IL-1), a cytokine known to sustain the inflammatory responses initiated by skin keratinocytes, may have a role in PPP [2-4]. Therefore, IL-1 blockade is hypothesized to be effective in the treatment of PPP.

Anakinra for Pustular Psoriasis: Response in a Controlled Trial (APRICOT) is a randomised, doubleblind, placebo-controlled trial with two stages and an adaptive element which aims to determine the efficacy of anakinra in the treatment of adults with palmoplantar pustulosis (PPP). Full details on the rationale and background to the trial can be found in the published study protocol [5].

Since PPP is a rare condition and prior existing proof-of-concept data for anakinra are limited, APRICOT was designed to include two stages. Prior to the completion of a fully powered efficacy assessment (stage two), we compared the treatment arms at the end of stage one to provide reassurance for safety and evidence for potential treatment benefit. Stage one was also designed to confirm the primary outcome measure for the fully powered treatment comparison in stage two. The statistical analysis plan, which details the analyses undertaken in stage one, has previously been published [6]. The current document describes the statistical analyses to be undertaken at the end of stage two (the final analysis of the double-blind randomised controlled trial). The plan was approved by Catherine Smith (Chief investigator), Victoria Cornelius (Senior statistician), Suzie Cro (Trial Statistician) and Edel O'Toole (Trial Steering Committee chair) prior to database lock and to the unblinding of the trial statistician following database lock.

\section{Trial status}

Recruitment to APRICOT began in October 2016. Stage one recruitment completed in September 2017 when a total of 24 patients had been randomised. Interim analysis at the end of Stage one, involving $n=24$ patients, compared treatment arms to ensure sufficient efficacy following the pre-specified APRICOT stage one statistical analysis plan (SAP) [6]. The trial passed the stop/go efficacy criteria to progress to stage two, and a decision to embark on stage two, which involved a further 40 participants and was powered to determine efficacy, was made by the independent data monitoring committee (IDMC).
At the end of stage one, the IDMC assessed the distributions and reliability of two candidate outcomes to establish which one should be confirmed as the primary outcome. Following an assessment of reliability (as prespecified in the stage one SAP [6]), the primary outcome for stage two was chosen to be the change in disease activity over 8 weeks, adjusted for baseline, measured using Palmoplantar Pustulosis Psoriasis Area and Severity Index (PPPASI).

In July 2019 an optional open label extension was added to the trial and offered to all patients who complete the 8-week treatment period and the 12week follow up visit, including those who had completed the treatment period in previous years. Following slower than projected recruitment rates, all aspects of the trial design were critically reviewed, and an open label extension was one modifiable element. The primary purpose of the open label extension was to enhance the slow recruitment to the randomised, double-blind, placebo-controlled study, so that all participants have the potential opportunity to access anakinra. This change was informed by feedback from recruiting clinicians and patient reasons recorded for declining to take part in the trial. Recruitment to stage two is due to complete by the end of January 2020. Data collection for the double-blind randomised controlled trial is expected to complete by April 2020, and statistical analysis will be performed following data cleaning checks and database lock.

\section{Objectives}

The primary objective of APRICOT is to determine the efficacy of anakinra on the change in disease activity over 8 weeks, measured using the PPPASI, in the treatment of adults with PPP compared to placebo.

\section{Secondary objectives}

The secondary objectives of the trial include the following:

- Estimate the efficacy of anakinra on the change in disease activity over 8 weeks, measured using pustule count compared to placebo

- Compare the time to response of PPP and the relapse rate with anakinra to placebo

- Estimate the proportion of patients who achieve clearance of PPP with anakinra compared to placebo by 8 weeks

- Estimate the treatment effect of anakinra in pustular psoriasis at non-acral sites

- Estimate the treatment effect of anakinra in plaquetype psoriasis 
- Collate data on the adverse event profile and adverse reactions induced by anakinra and compare to placebo to evaluate the safety and tolerability of anakinra in the treatment of PPP

- Determine the effect of anakinra on patients quality of life compared to placebo

- Assess whether patients find treatment with anakinra acceptable or worthwhile

- Estimate adherence to treatment with anakinra

\section{Methods/Design}

\section{Trial design}

Anakinra for Pustular psoriasis: Response in a Controlled Trial (APRICOT) is a randomised, doubleblind, placebo-controlled trial with two stages and an adaptive element, followed by an open label extension. Participants will be allocated to 8 weeks of treatment with either anakinra or placebo and will return for a visit 4 weeks after treatment is completed (12 weeks). All participants who complete the 8-week treatment period and the 12-week follow-up visit will be offered the open label extension on anakinra for 8 weeks. The protocol for the APRICOT trial has been published previously and gives full details on the intervention under study and the inclusion and exclusion criteria [5].

\section{Randomisation and blinding}

Eligible participants with PPP will be randomised (1: 1) to receive treatment with anakinra or placebo via subcutaneous daily injections for 8 weeks. To ensure allocation concealment, participants will be randomised using an online randomisation system by the King's Clinical Trial Unit. Participants will be allocated to treatment arms using blocked randomisation stratified by centre.

Throughout the trial participants, research nurses, treating physicians and independent outcome assessors will be blinded to treatment assignment. The trial statistician will also be subgroup blind throughout the randomised trial. That is, the trial statistician will observe the data as group A versus group B, without knowing which treatments A and B refer to. The senior statistician who conducted the stage one analysis was subgroup-blind throughout stage one and was unblinded at the end of stage one.

\section{Outcomes}

\section{Primary outcome}

The primary outcome is the disease activity at 8 weeks measured using the Palmoplantar Pustulosis Psoriasis Area and Severity Index (PPPASI), adjusted for baseline PPPASI.

\section{Secondary outcomes}

Secondary outcomes for APRICOT include the

following:

Investigator assessed efficacy measures, which include

- Fresh pustule count on palms and soles at 8 weeks (measured at week 1, 4 and 8), adjusted for baseline

- Total pustule count on palms and soles at 8 weeks (measured at week 1, 4 and 8), adjusted for baseline

- PPP - Investigator's Global assessment (PPP-IGA) at 8 weeks (measured at week 1, 4 and 8), adjusted for baseline

- Time from randomisation to response of PPP (where response is defined as a $75 \%$ reduction in fresh pustule count compared to baseline)

- Time from randomisation to relapse (where relapse is defined as return to baseline fresh pustule count)

- Achievement of 'clear' on PPP-IGA, at 8 weeks

- Development of a disease flare (i.e., $>50 \%$ deterioration in PPPASI compared to baseline) at 8 weeks

- Pustular psoriasis at non-acral sites (not hands and feet), as measured by percentage area of involvement at 8 weeks (measured at week 1, 4 and 8 ), adjusted for baseline

- Plaque type psoriasis (if present) measured using Psoriasis Area and Severity Index (PASI) at 8 weeks (measured at week 4 and 8), adjusted for baseline.

Participant reported efficacy outcomes, which include

- Participant's Global Assessment (PGA, as clear, nearly clear, mild, moderate, severe, very severe) over 8 weeks adjusted for baseline (measured at 1, 4, and 8 weeks)

- Palmoplantar Quality of Life Instrument score at 8 weeks, adjusted for baseline

- Dermatology Life Quality Index (DLQI) at 8 weeks adjusted for baseline

- EQ5D-3 L at 8 weeks adjusted for baseline

- Treatment acceptability (i.e., whether the treatment is 'worthwhile') evaluated using a brief questionnaire with a response scale of 1-5 at week 12 (after the last treatment dose at the end of the study, prior to the final safety visit)

- Adherence to treatment measured by self-recall and responses to daily text messages over 8 weeks of treatment.

Safety measures, which include 
- Serious infection as defined by any infection leading to death, hospital admission or requiring IV antibiotics

- Neutropenia (i.e., neutrophil count of $\leq 1.0 \times 10^{9} / 1$ on at least one occasion)

- Serious adverse events (SAE), Serious adverse reactions (SAR), or Unexpected serious adverse reactions (USAR), which include any adverse event, adverse reaction or unexpected adverse reaction, respectively, that results in death, is lifethreatening, required hospitalisation or prolongation of existing hospitalisation, results in persistent or significant disability or incapacity, or consists of a congenital anomaly or birth defect

- Adverse events (AE) and Adverse reactions (AR) including unexpected adverse reactions (UAR).

Additional exploratory/mechanistic outcomes will be collected during APRICOT. These outcomes will not contribute to the trial's main findings and primary results publication, so they do not form part of the main trial statistical analysis plan and will be described in more detail in a separate analysis plan.

\section{Sample size}

The sample size for APRICOT was undertaken at the design stage and prior to the completion of stage one, when the primary outcome of the main trial analysis was unknown. Consequently, the sample size was calculated using a standardised effect size. Given the high patient burden due to the requirement for daily self-administered subcutaneous injections and costs of the drug, an effect size of 0.9 Standard Deviations (SDs) was chosen to be the minimum important difference to detect with good power. Larger effect sizes have been reported when oral retinoids are used as the recommended systemic intervention for pustular psoriasis [1, 7]. With $90 \%$ power and a $5 \%$ significance level, for the detection of a difference of 0.9 $\mathrm{SD}$, a sample size of 27 per arm is required. To allow for a conservative approximate $15 \%$ withdrawal rate, 32 participants per arm $(N=64$ in total $)$ are required.

After recruitment had been extended by an extra 12 months, by November 2019, 57 patients had been randomised into the APRICOT trial. The APRICOT Trial Management Group (TMG) met to discuss the lower than anticipated recruitment and the studies statistical power was considered for various sample size numbers as a contingency in the event of lower than planned recruitment. To detect a difference of 0.9 SD, with $80 \%$ power and a $5 \%$ significance level, while allowing for a conservative approximate 15\% withdrawal rate, a sample size of 25 per $\operatorname{arm}(N=50$ in total) is required. Consequently, the decision was made to allow the trial to continue to recruit as many patients as possible within the funding constraints, given at least $80 \%$ power will be achieved.

\section{Statistical analysis plan \\ General analysis principles}

The final (stage two) analysis will be performed after all recruited participants have completed 20 weeks of follow-up post-treatment initiation. Analyses will be carried out by the sub-group-blinded trial statistician and will follow the intention-to-treat (ITT) principle. That is, all eligible randomised participants with baseline and at least one recorded outcome (over 8 weeks) will be analysed in the treatment arms to which the participant was allocated, regardless of the treatment subsequently received. The safety set (SS) population consists of all participants who received at least one dose of the assigned intervention and will be used in the analysis to describe adverse events.

All regression analyses will include adjustment for centre where appropriate, as this was a stratification factor in the randomisation; therefore, inclusion of this adjustment is necessary in the analysis to maintain the correct type I error rate [8, 9]. Additionally, for continuous outcomes, the outcome measured at baseline will be included in regression analyses to increase the power [10]. All confidence intervals will be two-sided and at the $95 \%$ level. A $p$-value $<0.05$ will be interpreted as statistically significant for the primary outcome.

\section{Recruitment and participant flow}

The number of participants randomised will be summarised by treatment arm and study centre (Appendix in Table 3). To summarise the patient flow through the trial, a Consolidated Standards of Reporting Trials (CONSORT) flow chart will be constructed [11] see (Fig. 1). This will include the number of patients screened, eligible and randomised into the trial, withdrawing from treatment and lost to follow-up, and the number included in the analyses.

\section{Baseline comparability of randomised groups}

Baseline characteristics will be summarised by randomised treatment arm. The variables to be summarised are presented in Appendix in Table 4. Categorical variables will be summarised by number and percentage in each category. Continuous variables will be summarised by mean and standard deviation for approximately normally distributed variables or median and interquartile range for non-normally distributed variables. No formal statistical tests will be performed because any differences between treatment arms at 


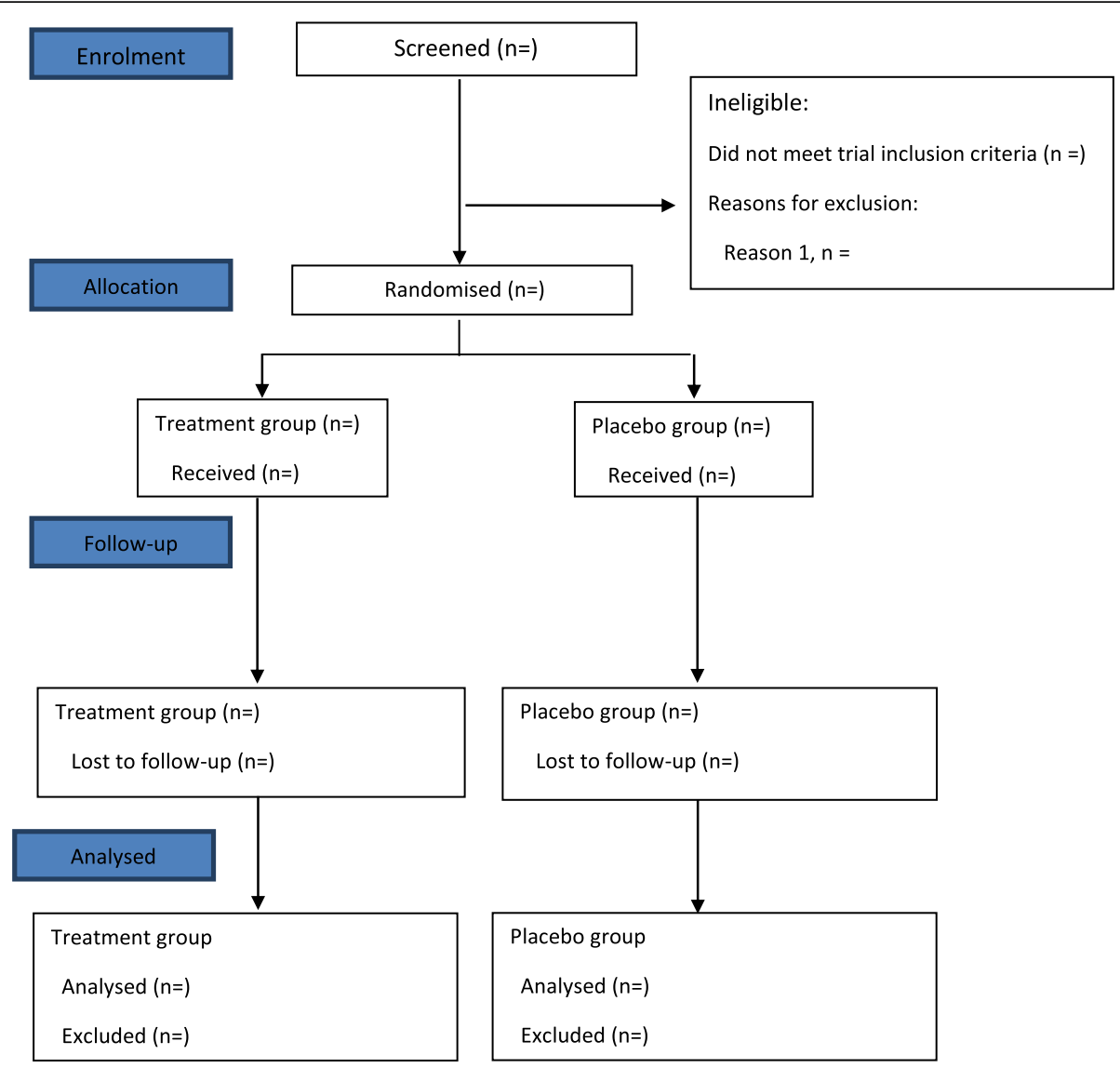

Fig. 1 Template CONSORT diagram for APRICOT

baseline will be the result of chance rather than bias due to randomisation.

\section{Withdrawals, loss to follow-up and missing data}

The number withdrawing from the trial, including those lost to follow-up, will be reported by treatment arm and time point along with the reasons for the withdrawal. The overall loss to follow-up will be tabulated by treatment arm and visit. The proportions of participants missing PPPASI values (primary outcome) will be summarised in each arm and at each time point for which measurement is planned (see Appendix in Tables 5, 6, 7 and 8).

\section{Adherence to allocated treatment}

The number discontinuing the trial drug will be reported by treatment arm and week along with the reasons for the discontinuations (Appendix in Tables 9 and 10). Self-reported treatment adherence, as measured by responses to daily text messages and selfreported by patients using a paper trial diary or verbally self-recalled at study visits, will be reported by treatment arm and week for patients who have not yet discontinued the treatment or withdrawn from the study by the given week (Appendix in Table 11). An injection will be classed as being received if either a SMS response of 'Yes' is recorded for the day in question or if self-reported as a 'Yes'. The adherence to the planned visit windows will also be summarised by treatment arm and visit (Appendix in Table 12).

\section{Rescue therapy, topical therapy and prohibited medication}

The proportion of participants using investigatordirected 'rescue' medication, as summarised in Table 1, in the form of potent corticosteroid (e.g., mometasone furoate, betamethasone valerate ointment or cream) and the duration of use and amount used will be summarised by treatment arm (Appendix in Tables 13, 14 and 15). We will plot histograms for the number of days of use of rescue therapy by treatment arm, plot the proportion of participants on rescue therapy over time and the cumulative proportion of participants initiated on rescue therapy over time. 
Table 1 Summary of concomitant therapy rules

\begin{tabular}{ll}
\hline Prohibited & Very potent topical corticosteroids (e.g., Dermovate) \\
& Any topical treatment that is likely to impact signs \\
& and symptoms of PPP (e.g., corticosteroids, vitamin D \\
& analogues, calcineurin inhibitors, retinoids, keratolytics, \\
& tar or urea) \\
& Phototherapy or PUVA \\
& Methotrexate, Cyclosporine, Acitretin, Alitretinoin, FAE \\
& Etanercept or Adalimumab \\
& Infliximab or Ustekinumab or Secukinumab \\
& Other TNF antagonists \\
& Other systemic immunosuppressive therapy \\
& Other investigational monoclonal antibody \\
& Other investigational drugs \\
Allowable topical & Emollients \\
therapy & Topical hydrocortisone, antihistamine for injection - \\
& site reactions \\
& Mild topical corticosteroids for the treatment of \\
& psoriasis at sites other than hands and feet applied \\
& with gloves \\
'Rescue' topical & Potent corticosteroid OD. To be dispensed only by \\
therapy & the study team, at the Investigator's discretion. \\
& Amounts prescribed to be recorded. \\
\hline
\end{tabular}

Where data allows, we will also summarise the overall proportion of participants using topical therapy during the treatment period, the duration of use and the amount used; histograms for the number of days of use of topical therapy will be constructed by treatment arm, and we will plot the proportion of participants on topical therapy over time.

If any prohibited medications are used (as defined in Table 1), we will also summarise the proportion of participants using prohibited medication, the prohibited medication used, the duration of use and the amount used.

\section{Descriptive statistics for outcome measures}

Descriptive statistics will be presented for all outcome measures by treatment arm. For each primary and secondary outcome that is recorded at multiple time points, the outcome will be summarised by visit and treatment arm (Appendix in Tables 16, 17, 18, 19, 20, 21, 22 and 23). Summary statistics with 95\% confidence intervals will also be plotted in line graphs for each outcome across time by intervention. Only participants with a completely recorded outcome will be used to calculate the summary measures.

\section{Adverse event reporting}

Information on adverse events will be collected by means of spontaneous reports from participants and carers, clinical observation and clinical examinations and blood tests. A safety set (SS) population will be used for describing adverse events. This SS population will include all participants who receive at least one injection of study drug or placebo. For each event, local clinical investigators rate the relationship to the study medication as none/unlikely/possible/likely/definite. Adverse Reactions (AR) consist of the subset of non-serious adverse events (AE) rated to have a possible/likely/definite relationship with the study medication. Serious Adverse Reactions (SAR) consist of the subset of serious adverse events (SAE) rated to have a possible/likely/definite relationship with the study medication. If the event is considered related to the study medication, then local clinical investigators will also rate whether the reaction was unexpected (Yes/No). Events will be coded using terms of the clinical investigators choosing with reference to Medical Dictionary for Regulatory Activities (MedDRA) at the 'Preferred Terms' level.

Adverse events will be summarised by type (AE, AR, unexpected adverse reactions (UAR, a subset of the ARs), serious adverse events (SAE), serious adverse reactions (SAR, a subset of the SAEs) and unexpected serious adverse reactions (USAR, a subset of the SARs)), and by treatment arm. Adverse events will be tabulated by treatment group for both the number of events and the number of participants with the type of event.

A listing will be produced detailing all Serious Adverse Events (SAEs) and Reactions (SARs). Nonserious adverse events and reactions will be listed by MedDRA preferred term level. Non-serious adverse events will also be summarised by MedDRA system organ class and intensity (subjectively assessed by local clinical investigators as mild/moderate/severe). The number of events related to an infection will be tabulated. Details will be provided for those events related to infection, including the treatment prescribed, where applicable.

No hypothesis testing will be undertaken for adverse event outcomes, but approaches to assess signals for ARs will be explored, as described below (Appendix in Tables 24, 25, 26, 27, 28, 29, 30, 31 and 32). An adverse event of particular interest is injection site reaction. We will also separately analyse serious infections, defined by any infection leading to death, prolonged hospital admission or requiring IV antibiotics, as described below in further detail.

\section{Analysis of primary outcome}

The mean difference in the week 8 PPPASI, adjusted for baseline, between the two treatment groups will be estimated using a mixed-effects linear (Gaussian) regression model. The model will include a random intercept for participants with fixed effects for time, treatment group, time-by-treatment group interaction 
and baseline PPPASI. Centre will be included in the model either as a random or fixed effect depending on the total number of centres recruiting to the study and the average number of participants recruited from each centre. The estimated treatment effect at 8 weeks will be reported with a 95\% confidence interval and corresponding $p$-value. As the model adjusts for baseline PPPASI, this is equivalent to analysing the change from baseline with adjustment for baseline [12]. The main conclusion of the trial will be based on this analysis time point. We will also report the treatment effect at weeks 1 and 4 .

Approximately 15 centres are anticipated to recruit, and therefore, a relatively small number of participants will be recruited per centre. Since random centre effects have been shown to be superior to fixed effects in terms of power and precision when the number of participants per centre is small, and equivalent to fixed effects when the number of participants per centre is larger $[9,13]$, the default option will be to include centre as a random effect. With centre as a random effect, where $Y_{i j k}$ denotes the PPPASI measurement for participant $i$ at time $j$ from centre $k$, the primary analysis model will be model A:

$$
\begin{aligned}
Y_{i j k}= & \beta_{0}+\beta_{1} T R T_{i}+\beta_{2} \text { PPPASI }_{i}^{0}+\beta_{3} t_{4}+\beta_{4} t_{8} \\
& +\beta_{5} t_{4} * T R T_{i}+\beta_{6} t_{8} * T R T_{i}+b_{1, i}+b_{2, k}+e_{i j k}
\end{aligned}
$$

where $j=1$ to 3 time points (week 1,4 , and 8 ), $i=1$ to 64 participants, and $\mathrm{k}=1$ to $\sim 15$ centres; $T R T_{i}$ is the dummy variable $\left(T R T_{i}=0\right.$ or 1$)$ for participant $i$; $P P P A S I_{i}^{0}$ is the baseline PPPASI for participant $i$; $t_{x}$ is the dummy variable for time $(=0$ or 1$)$ at time point $x$ weeks; Week 1 is represented by $t_{4}=0$ and $t_{8}=0$; and $b_{1, i} \sim N\left(0, \sigma_{b 1}^{2}\right), b_{2, k} \sim N\left(0, \sigma_{b 2}^{2}\right)$, and $e_{i j k} \sim N\left(0, \sigma_{e}^{2}\right)$,

Within model $\mathrm{A}, b_{1, i}$ and $b_{2, k}$ are random intercepts at the participant level and centre level, respectively. Each of $b_{1, i}, b_{2, k}$ and $e_{i j k}$ are assumed to follow normal distributions. An unstructured covariance matrix will be used [14]. The treatment effect at 8 weeks, $\beta_{1}+\beta_{6}$,will be of primary interest. If, however, the variation between centres is low and the model fails to converge, then centre will be treated as a fixed effect instead. With centre as fixed, where $y_{i j k}$ denotes the PPPASI measurement for participant $i$ at time $j$ from centre $k$, the primary analysis model will be model B:

$$
\begin{aligned}
Y_{i j k}= & \beta_{0}+\beta_{1} T R T_{i}+\beta_{2} P P P A S I_{i}^{0}+\beta_{3} t_{4}+\beta_{4} t_{8} \\
& +\beta_{5} t_{4} * T R T_{i}+\beta_{6} t_{8} * T R T_{i}+\beta_{7 \mathrm{k}} \text { CENTRE }_{i} \\
& +b_{1, i}+e_{i j k}
\end{aligned}
$$

where $\mathrm{j}=1$ to 3 time points (week 1,4 , and 8) and $\mathrm{i}=1$ to 64 participants; $T R T_{i}$ is the dummy variable $\left(T R T_{i}=0\right.$ or 1) for participant $i$;PPASI $I_{i}^{0}$ is the baseline PPPASI for participant $i$;

$t_{x}$ is the dummy variable for time $(=0$ or 1$)$ at time point $\mathrm{x}$ weeks; Week 1 is represented by $t_{4}=0$ and $t_{8}=$ $0 ; \beta_{7 \mathrm{k}}$ is a dummy variable for each centre $\mathrm{k}$; for centre $1, \beta_{7 \mathrm{k}}$ will be constrained to be 0 ; and $b_{1, i} \sim N\left(0, \sigma_{b 1}^{2}\right)$ and $e_{i j k} \sim N\left(0, \sigma_{e}^{2}\right)$,

Within model $\mathrm{B}, b_{1, i}$ is a random intercept at the participant level. Both $e_{i j k}$ and $b_{1, i}$ follow normal distributions. An unstructured covariance matrix will be used. The treatment effect at 8 weeks, $\beta_{1}+\beta_{6}$, will be the mean treatment effect of primary interest.

Models will be fitted using restricted maximum likelihood (REML). Both models make assumptions about random effects distributions, correlation structure and residuals, which will all be investigated. If including centre as a fixed effect results in unstable model estimates, e.g., if a number of sites $(>1)$ have very few randomisations $(\leq 3)$, we will exclude centre from the model (model C). Stata code for the primary outcome analysis is displayed in Table 2.

\section{Sensitivity analysis of primary outcome}

Every effort will be made to obtain follow-up data for all participants including those who stop treatment. The primary analysis will include all observed data and employ maximum likelihood estimation.This approach is efficient for handling missing outcome data under the missing-at-random assumption (MAR). That is, the probability of missing data is assumed to not be dependent on the values of the unobserved data themselves, but instead conditional on the observed values of the variables included in the analysis model.

Sensitivity analyses addressing the impact of missing data will explore departures from the main MAR analysis assumption and potential missing not at random (MNAR) mechanisms using Multiple Imputation (MI) and a pattern mixture approach (Carpenter and Kenward, 2008) for all patients on the primary outcome following the ITT principle. Imputation under MAR will initially be performed separately within each treatment arm using chained equations following the guidance suggested by White et al. [15]. The variables in the imputation model will be the same as those in the analysis model without including more auxiliary variables after taking into account the relatively small sample size of this study [16]. Imputations will then be modified to investigate the impact of a better or poorer response than that predicted by MAR (lower/ higher PPPASI scores) for participants with missing data. To do this, we will define $\delta$ as the postulated mean difference in the rate of change of the PPPASI 
Table 2 Statistical analysis code for the primary outcome

\begin{tabular}{|c|c|c|}
\hline Model & Analysis method & Stata code for analysis \\
\hline A & $\begin{array}{l}\text { Primary analysis: The PPPASI will be analysed using a linear mixed effects model, with } \\
\text { fixed effects for time, treatment group, time-by-treatment group interaction and } \\
\text { baseline PPPASI. The model will include a random intercept for participants and centre } \\
\text { of recruitment. }\end{array}$ & $\begin{array}{l}\text { mixed pppasi treat\#\#i.time base_pppasi /// } \\
\text { || centre: \|| id:, covariance(unstructured) reml }\end{array}$ \\
\hline B & $\begin{array}{l}\text { If Model A fails to converge: Model A without the random-effect for centre, centre will } \\
\text { instead be included as a fixed effect }\end{array}$ & $\begin{array}{l}\text { mixed pppasi treat\#\#.time base_pppasi i.centre /// } \\
\text { \|l id:, covariance(unstructured) reml }\end{array}$ \\
\hline$C$ & $\begin{array}{l}\text { If Model A fails to converge and }>1 \text { site has } \leq 3 \text { randomised: Primary analysis model } \\
\text { excluding centre as a random or fixed effect }\end{array}$ & $\begin{array}{l}\text { mixed pppasi treat\#\#i.time base_pppasi /// } \\
\text { || id:, covariance(unstructured) reml }\end{array}$ \\
\hline
\end{tabular}

score between the observed and unobserved cases for each week unobserved. For each participant in each intervention arm, we will then modify the MAR imputed observations accordingly by $\delta$. Imputed data sets will be analysed using the primary analysis model. Results will be combined across imputed data sets using Rubin's rules. We will repeat the analysis for a range of $\delta$ corresponding to $+/-10,20,30,40$ and $50 \%$ of the rate of change of the PPPASI over 8 weeks in all observed participants. We will also consider the possibility that data is missing informatively in one arm only. Only imputations for active arm participants will be modified for a range of $\delta$ corresponding to $+/-10,20,30,40$ and $50 \%$ of the rate of change of the PPPASI observed over 8 weeks in the active arm and the primary analysis repeated. Subsequently, only imputations for placebo participants will be modified as described above. Fifty imputations will be run for each MI analysis.

\section{Supplementary analysis for the primary outcome}

Four supplementary analyses are pre-planned for the trials primary outcome:

1. Supplementary analysis accounting for use of rescue therapy-Data after the initiation of rescue therapy will be set as missing. The primary analysis model will be fitted to data prior to the use of rescue therapy along with all observed data for patients who do not initiate rescue therapy to estimate the treatment effect in the absence of rescue therapy because participants who were initiated on rescue therapy are assumed to have had a similar outcome to those observed with the same history and profile in the absence of rescue therapy (MAR). Since the rescued participants would typically have had worse outcomes than those observed in the absence of rescue therapy, a pattern-mixture MI approach will subsequently be used to explore the impact of worse outcomes among the participants initiated on rescue therapy. Imputation under MAR will initially be performed as described above. We will define $\delta_{\mathrm{R}}$ as the postulated mean difference in the rate of change of the PPPASI between the observed and rescued cases for each week post-rescue. For each participant initiating rescue therapy, we will then modify their MAR imputed observations accordingly by $\delta_{R}$. Imputed datasets will be analysed using the primary analysis model. Results will be combined across imputed datasets using Rubin's rules. We will repeat the analysis for a range of $\delta_{R}$ corresponding to $10 \%, 20 \%, 30 \%, 40 \%$ and $50 \%$ of the change in the PPPASI observed in those with complete data over 8 weeks. For each MI analysis, 50 imputations will be run. These deltaadjusted sensitivity analyses will each provide an estimate of the treatment effect in the absence of rescue therapy, where participants who were initiated on rescue therapy are assumed to have had a specific poorer outcome than those observed with the same history and profile in the absence of rescue therapy.

2. Supplementary analysis accounting for use of prohibited medication-Data post initiation of rescue therapy and prohibited medication will be set as missing, and the analytical approach outlined above for accounting for rescue therapy will be adopted, but applied to individuals with data missing after rescue therapy or after prohibited medication use.

3. Supplementary analysis accounting for use of topical therapy-Where data allow, data will be set as missing when participants are on topical therapy at the time of the study follow-up visit. The primary analysis model will be fitted to data for participants not on topical therapy, along with all observed data for patients who do not initiate topical therapy. This analysis will provide an estimate of the treatment effect in the absence of topical therapy, under the assumption that 
participants who were initiated on topical therapy would have had a similar outcome to those observed with the same history and profile in the absence of topical therapy (MAR). Subsequently, data after the initiation of rescue therapy and prohibited medication will be set as missing, as well as data for participants while on topical therapy, and the analytical approach outlined above for accounting for rescue therapy will be adopted, but applied to individuals who are missing data from their time on topical treatment or after rescue therapy or prohibited medication use.

4. Supplementary analysis to estimate the complier average causal effect-For each participant, the proportion of injections received relative to injections planned $(8 \times 7=56)$ will be calculated and summarised based on the recorded daily adherence data. The complier average causal effect (CACE) will be estimated by a two-stage least squares instrumental variable regression for the primary endpoint (using ivregress 2sls in Stata). Here, we will initially define a 'complier' as an individual who complete more than $50 \%$ of the injections, that is, injections received relative to injections planned for the 8-week study period. Randomisation will be used as an instrumental variable for treatment received with adjustment for centre and baseline PPPASI on the week 8 outcome. Subsequently, we will alternatively define a 'complier' as an individual who completes $\geq 60 \%, \geq 70 \%$, $\geq 80 \%$ and $\geq 90 \%$ of injections, and we will employ the same analysis approach to address the impact of alternative definitions of compliance. If including centre as a fixed effect results in unstable model estimates, for example, if a number of sites have very few randomisations, we will exclude centre from the model and adjust for baseline PPPASI only.

\section{Analysis of secondary outcomes}

Continuous secondary outcomes (fresh pustule count, total pustule count, plaque-type psoriasis - PASI, palmoplantar quality of life instrument and EQ5D-3 L utility score) will each be analysed in a similar fashion to the primary PPPASI outcome using a linear mixed effects model. Similar to the primary analysis model, each model will include fixed effects for treatment group, time, treatment group-by-time interaction and baseline value of the associated outcome. A random patient intercept will also be included in each of the models. If convergence problems are experienced, the approach outlined for the primary outcome will be followed.
Binary secondary outcomes (clear on PPP-IGA, development of disease flare, serious infection, and neutropenia) will each be analysed with a mixed logistic regression model. The models will include a fixed effect for treatment group and centre as a random intercept. If convergence problems are experienced, the approach outlined for the primary outcome will be followed. The treatment odds ratio (OR) will be reported with $95 \% \mathrm{CI}$.

Ordinal secondary outcomes (PPP-IGA, PGA) will be analysed with mixed ordinal logistic regression models. The models will include a random intercept for participant and fixed effects for time, treatment group, time-by-treatment group interaction and baseline value of the outcome. Centre will be included as a random effect initially, but if non-convergence occurs, centre will be treated as a fixed effect or will be excluded if unstable model estimates occur. We will report the change in odds of a one-category increase in the outcome for patients in the active arm relative to placebo. The ordinal logistic regression model makes assumptions about proportional odds which will be checked for each outcome. If the proportional odds assumption appears to be strongly violated, a mixed effect multinomial logit model may alternatively be fitted.

For the time to event outcomes (time to response of PPP, time and to relapse), we will initially plot Kaplan Meier curves to visualise the unadjusted response rate over time by treatment group. Since outcomes are observed at relatively few discrete time intervals (week 1, 4, 8 and 12) random-intercept complementary log-log models will be used to estimate the treatment effects for the time to event outcomes. The model will include treatment group as a fixed effect and a random intercept for centre. The subject specific (conditional) hazard ratio for the treatment group will be reported with 95\% CI. If convergence problems are experienced by including centre as a random effect, the approach outlined above will be followed. The complementary log-log model is appropriate for the discrete nature of the survival data [17]. The model corresponds to proportional hazards in continuous time. The proportional hazards assumption will be checked. If this assumption is violated, an alternative parameterisation will be used e.g., including a treatment-by-time interaction that varies the effect by time or restrictsing the observation time.

For adverse events and reactions, a volcano plot, constructed as described in [18], which plots the risk difference of the non-serious adverse events and reactions by the MedDRA preferred term between the treatment arms against the $p$-value from a Fishers' exact test, will be examined to identify the events 
with the strongest evidence for between arm differences. A volcano plot will also be constructed to examine non-serious adverse events and reactions by MedDRA system organ class. Because few SAEs are anticipated, the SAEs will be evaluated individually, but they may also be included in these plots if thought to aid review. Where useful negative binomial or zero-inflated Poisson regression models will be used to estimate relative risks, risk differences and incidence rate ratios of non-serious events by MedDRA preferred term and/or system organ class. Where suitable, the timing of adverse events (using hazard plots) by treatment arm will be examined.

\section{Exploratory analysis}

A longitudinal analysis will be undertaken using a linear (Gaussian) mixed model to determine the treatment difference in PPPASI at 12 weeks. The analysis model will be the same as in the primary analysis but will include additional data at 12 weeks. The treatment effect for PPPASI at 12 weeks will be estimated and reported with $95 \%$ CI.

Since palmar disease may respond more quickly than plantar disease, exploratory analysis will separately estimate the efficacy of anakinra on the (i) disease activity at 8 weeks, measured using fresh pustule count on the palms, adjusted for baseline compared to placebo and (ii) disease activity at 8 weeks, measured using fresh pustule count on the soles, adjusted for baseline compared to placebo. For each of the palms and soles fresh pustule counts, a linear mixed effects model will be used, which includes fixed effects for treatment group, time, treatment group-bytime interaction, and baseline value of the associated outcome. A random patient intercept will also be included in each of the models. If convergence problems are experienced, the approach outlined for the primary outcome will be followed.

\section{Missing baseline data}

Missing baseline data are unlikely to be problematic for the analysis because the baseline values will be collected at the first clinic visit and centre will naturally be complete. However, if baseline values are missing, to avoid a loss of power within the analyses which adjust for baseline values, these values will be imputed with the mean baseline value calculated from the non-missing values using pooled data from both treatment groups. This technique improves the statistical efficiency in the estimation of the treatment effect and is justifiable since randomisation ensures that baseline values are independent of treatment group $[19,20]$.

\section{Missing outcome data}

The primary analysis will use all observed outcome data and will be conducted under the MAR assumption. As detailed above, we will conduct sensitivity analysis to assess the impact of departures from the MAR assumption on the results of the primary analysis. Secondary analyses will use all available outcome data and will also be conducted under the MAR assumption.

\section{Interim analysis and data monitoring}

The IDMC will review safety and efficacy data at time points of their choosing. No statistical hypothesis testing will be completed for the IDMC. Stage one analysis did not involve formal statistical hypothesis testing; as a result, no adjustment for interim analyses has been made.

\section{Multiple comparisons}

No multiplicity adjustments will be performed for the analysis of secondary outcomes, and results will be viewed as hypothesis-generating.

\section{Discussion}

We have described in detail the planned analysis for the final stage (stage two) of APRICOT following the guidelines for the content of statistical analysis plans in clinical trials [21]. The APRICOT trial will establish the role of anakinra in treating PPP. This pre-specified statistical analysis plan will increase the transparency of the data analysis and reporting.

\section{Trial registration}

ISCRTN ISCRTN13127147 registered on 1 August 2016, http://www.isrctn.com/ISRCTN13127147. EudraCT Number: 2015-003600-23 registered on 1 April 2016, https://www.clinicaltrialsregister.eu/ctr-search/search?query $=2015-003600-23$.

\section{Appendix}

Table 3 Randomisation by centre and treatment group

\begin{tabular}{llll}
\hline & $\begin{array}{l}\text { Group A } \\
N(\%)\end{array}$ & $\begin{array}{l}\text { Group B } \\
N(\%)\end{array}$ & Total \\
\hline $\begin{array}{l}\text { Number randomisation to date } \\
\text { (dd/mm/yyy) }\end{array}$ & & \\
Study centre & & \\
Centre 1 & & \\
Centre 2 & & \\
Centre 3 & & \\
Centre 4 & \\
\hline
\end{tabular}


Table 4 Baseline demographics by treatment group

\begin{tabular}{|c|c|c|}
\hline Characteristic & $\begin{array}{l}\text { Group A } \\
\mathrm{N}=\end{array}$ & $\begin{array}{l}\text { Group B } \\
\mathrm{N}=\end{array}$ \\
\hline \multicolumn{3}{|l|}{ Age } \\
\hline \multicolumn{3}{|l|}{ N (Nmissing) } \\
\hline \multicolumn{3}{|l|}{ Mean (SD) } \\
\hline \multicolumn{3}{|l|}{ Median (IQR) } \\
\hline \multicolumn{3}{|l|}{ Min-Max } \\
\hline \multicolumn{3}{|l|}{ Gender } \\
\hline \multicolumn{3}{|l|}{ N (Nmissing) } \\
\hline \multicolumn{3}{|l|}{ Male, n (\%) } \\
\hline \multicolumn{3}{|l|}{ Female, n (\%) } \\
\hline \multicolumn{3}{|l|}{ Ethnicity } \\
\hline \multicolumn{3}{|l|}{ White, n (\%) } \\
\hline \multicolumn{3}{|l|}{ Asian or Asian British, n (\%) } \\
\hline \multicolumn{3}{|l|}{ Black or Black British, n (\%) } \\
\hline \multicolumn{3}{|l|}{$\begin{array}{l}\text { Chinese, Japanese, Korean, } \\
\text { Indochinese, n (\%) }\end{array}$} \\
\hline \multicolumn{3}{|l|}{ Mixed race, n (\%) } \\
\hline \multicolumn{3}{|l|}{ Other, n (\%) } \\
\hline \multicolumn{3}{|l|}{ Smoking status } \\
\hline \multicolumn{3}{|l|}{ Current smoker, n (\%) } \\
\hline \multicolumn{3}{|l|}{ Ex-smoker, n (\%) } \\
\hline \multicolumn{3}{|l|}{ Non-smoker, n (\%) } \\
\hline \multicolumn{3}{|l|}{ PPPASI } \\
\hline \multicolumn{3}{|l|}{ N (Nmissing) } \\
\hline \multicolumn{3}{|l|}{ Mean (SD) } \\
\hline \multicolumn{3}{|l|}{ Median (IQR) } \\
\hline Min-Max & & \\
\hline
\end{tabular}

Fresh pustule count (palms and soles)

$$
\begin{aligned}
& \text { N (Nmissing) } \\
& \text { Mean (SD) } \\
& \text { Median (IQR) } \\
& \text { Min-Max }
\end{aligned}
$$

Fresh pustule count (palms)

N (Nmissing)

Mean (SD)

Median (IQR)

Min-Max

Fresh pustule count (soles)

$\mathrm{N}$ (Nmissing)

Mean (SD)

Median (IQR)

Min-Max

Total pustule count (palms and soles)

$\mathrm{N}$ (Nmissing)

Mean (SD)
Table 4 Baseline demographics by treatment group (Continued)

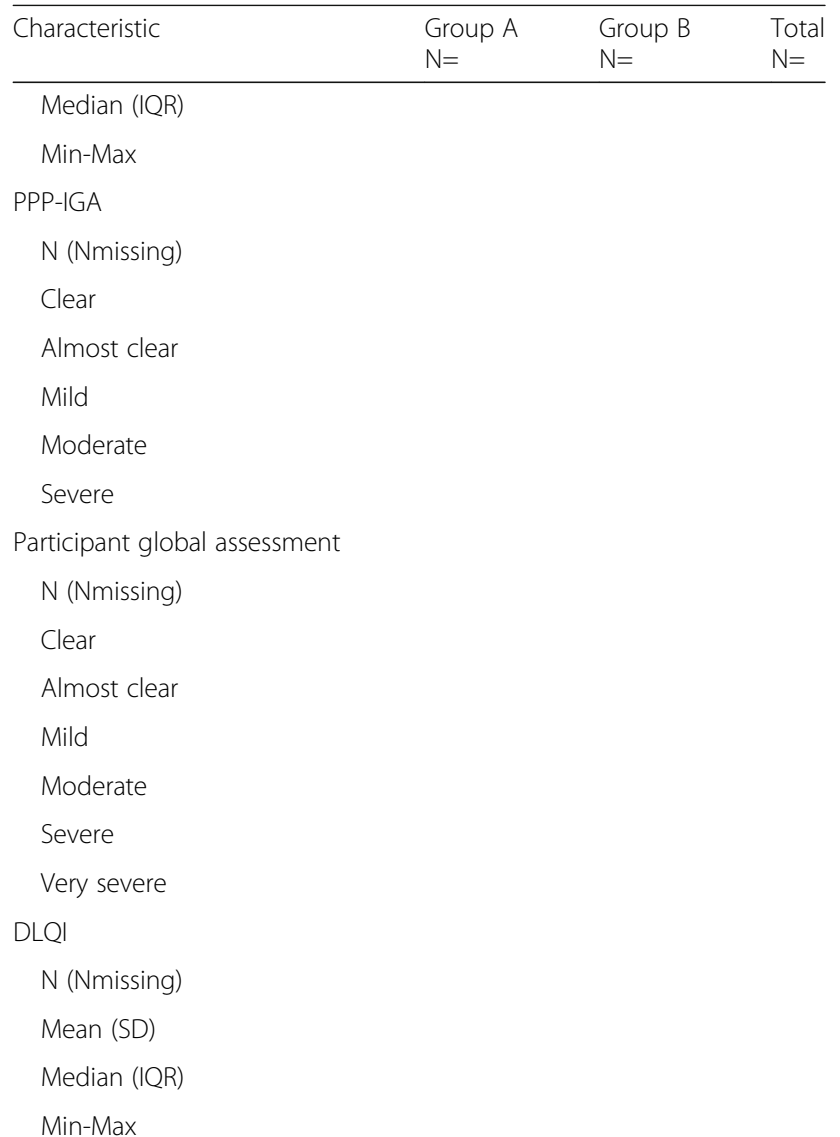

Pustular psoriasis at non acral sites (BSA)

$N$ (Nmissing)

Mean (SD)

Median (IQR)

Min-Max

Generalised plaque psoriasis - PASI

$\mathrm{N}$ (Nmissing)

Mean (SD)

Median (IQR)

Min-Max

Palmoplantar quality of life instrument

$\mathrm{N}$ (Nmissing)

Mean (SD)

Median (IQR)

Min-Max

EQ 5D- utility score

N (Nmissing)

Mean (SD)

Median (IQR)

Min-Max

EQ 5D-VAS 
Table 4 Baseline demographics by treatment group (Continued)

\begin{tabular}{llll}
\hline Characteristic & $\begin{array}{l}\text { Group A } \\
\mathrm{N}=\end{array}$ & $\begin{array}{l}\text { Group B } \\
\mathrm{N}=\end{array}$ & $\begin{array}{l}\text { Total } \\
\mathrm{N}=\end{array}$ \\
\hline $\mathrm{N}$ (Nmissing) & & \\
Mean (SD) & & \\
Median (IQR) & & \\
Min-Max & & \\
\hline
\end{tabular}

Table $\mathbf{5}$ Withdrawals from trial by treatment group

\begin{tabular}{llll}
\hline Point of Withdrawal: & Group A & Group B & Total \\
& $\mathrm{N}=$ & $\mathrm{N}=$ & $\mathrm{N}=$
\end{tabular}

Baseline date $(n, \%)$

By week $1(n, \%)$

By week $4(n, \%)$

By week $8(n, \%)$

By week $12(\mathrm{n}, \%)$

By week 20 (n, \%)

Table 6 Reasons for withdrawal by treatment group

\begin{tabular}{llll}
\hline Reason & $\begin{array}{c}\text { Group A } \\
\mathrm{N}=\end{array}$ & $\begin{array}{l}\text { Group B } \\
\mathrm{N}=\end{array}$ & $\begin{array}{l}\text { Total } \\
\mathrm{N}=\end{array}$ \\
\hline Lost to follow-up (n, \%) & & \\
Reason $2(n, \%)$ & & \\
Reason $3(n, \%)$ & & \\
Reason $4(n, \%)$ & & \\
\hline
\end{tabular}

Table 7 Loss to follow-up

\begin{tabular}{llll}
\hline Loss to follow-up & Group A & Group B & Total \\
& $\mathrm{N}=$ & $\mathrm{N}=\mathrm{N}=$
\end{tabular}

\section{Baseline}

Week $1(n, \%)$

Week $4(n, \%)$

Week $8(n, \%)$

Week $12(n, \%)$

Table 8 Missing data for PPPASI

\begin{tabular}{llll}
\hline Missing & Group A & Group B & Total \\
& $N=$ & $N=$ & $N=$
\end{tabular}

\section{Baseline}

Week $1(n, \%)$

Week $4(n, \%)$

Week $8(n, \%)$

Week $12(n, \%)$
Table 9 Permanent trial drug discontinuation

\begin{tabular}{|c|c|c|c|}
\hline Point of treatment discontinuation & Group A N= & $\begin{array}{l}\text { Group B } \\
N=\end{array}$ & $\begin{array}{l}\text { Total } \\
N=\end{array}$ \\
\hline \multicolumn{4}{|l|}{ Baseline $(n, \%)$} \\
\hline \multicolumn{4}{|l|}{ Week $1(n, \%)$} \\
\hline \multicolumn{4}{|l|}{ Week $2(n, \%)$} \\
\hline \multicolumn{4}{|l|}{ Week $3(n, \%)$} \\
\hline \multicolumn{4}{|l|}{ Week $4(n, \%)$} \\
\hline \multicolumn{4}{|l|}{ Week $5(n, \%)$} \\
\hline \multicolumn{4}{|l|}{ Week $6(n, \%)$} \\
\hline \multicolumn{4}{|l|}{ Week $7(n, \%)$} \\
\hline Week 8 (n, \%) & & & \\
\hline
\end{tabular}

Table 10 Reasons for trial drug discontinuation

\begin{tabular}{llll}
\hline Reason & $\begin{array}{l}\text { Group A } \\
N=\end{array}$ & $\begin{array}{l}\text { Group B } \\
N=\end{array}$ & $\begin{array}{l}\text { Total } \\
N=\end{array}$ \\
\hline Reason $1(n, \%)$ & & \\
Reason $2(n, \%)$ & & \\
Reason 3 $(n, \%)$ & & \\
Reason $4(n, \%)$ & & \\
\hline
\end{tabular}

Table 11 Self-reported adherence to treatment group

\begin{tabular}{|c|c|c|c|c|c|c|c|}
\hline \multirow[t]{2}{*}{$\begin{array}{l}\text { Treatment } \\
\text { period }\end{array}$} & \multicolumn{2}{|c|}{$\begin{array}{l}\text { Mean number of doses } \\
\text { per week (SMS) }\end{array}$} & \multicolumn{2}{|c|}{$\begin{array}{l}\text { Mean number of doses } \\
\text { per week (Diary) }\end{array}$} & \multicolumn{3}{|c|}{$\begin{array}{l}\text { Mean number of doses } \\
\text { per week (Total*) }\end{array}$} \\
\hline & $\begin{array}{ll}\mathrm{N} & \text { Group A } \\
& \text { Mean } \\
& \text { (SD) }\end{array}$ & $\begin{array}{l}\text { Group B } \\
\text { Mean } \\
\text { (SD) }\end{array}$ & $\begin{array}{ll}\mathrm{N} & \text { Group A } \\
& \text { Mean } \\
& (\mathrm{SD})\end{array}$ & $\begin{array}{l}\text { Group B } \\
\text { Mean } \\
\text { (SD) }\end{array}$ & $\overline{\mathrm{N}}$ & $\begin{array}{l}\text { Group A } \\
\text { Mean } \\
\text { (SD) }\end{array}$ & $\begin{array}{l}\text { Group B } \\
\text { Mean } \\
\text { (SD) }\end{array}$ \\
\hline
\end{tabular}

Week 1

Week 2

Week 3

Week 4

Week 5

Week 6

Week 7

Week 8

*SMS and Diary data combined

Table 12 Adherence to visit windows

\begin{tabular}{|c|c|c|}
\hline \multirow[t]{3}{*}{ Visit } & \multicolumn{2}{|c|}{ Difference |expected - actual| } \\
\hline & $\begin{array}{l}\text { Group A } \\
N=\end{array}$ & $\begin{array}{l}\text { Group B } \\
N=\end{array}$ \\
\hline & $\bar{N} \quad$ Mean $(\min , \max )$ & Mean (min, max) \\
\hline \multicolumn{3}{|l|}{ Baseline } \\
\hline \multicolumn{3}{|l|}{ Week 1} \\
\hline \multicolumn{3}{|l|}{ Week 4} \\
\hline \multicolumn{3}{|l|}{ Week 8} \\
\hline \multicolumn{3}{|l|}{ Week 12} \\
\hline Week 20 & & \\
\hline
\end{tabular}


Table 13 Rescue therapy by treatment group

\begin{tabular}{|c|c|c|c|}
\hline Treatment given & Group A N= & Group B N= & $\begin{array}{l}\text { Total } \\
N=\end{array}$ \\
\hline \multicolumn{4}{|l|}{ Treatment $1(n, \%)$} \\
\hline \multicolumn{4}{|l|}{ Treatment $2(n, \%)$} \\
\hline \multicolumn{4}{|l|}{ Treatment $3(n, \%)$} \\
\hline Total & & & \\
\hline
\end{tabular}

Table 14 Rescue therapy by treatment group and time point of first initiation

\begin{tabular}{llll}
\hline Rescue initiation & Group A & Group B & Total \\
& $N=$ & $N=$ & $N=$
\end{tabular}

Prior to week $1(n)$

Prior to week $4(n)$

Prior to week $8(n)$

Prior to week $12(n)$

Prior to week $20(n)$

Total

Table 15 Days of use of rescue therapy and amount used

\begin{tabular}{ll}
\hline Rescue therapy & Treatment group \\
\cline { 2 - 2 }
\end{tabular}

Number of patients taking rescue therapy

Total no. of days of use

Mean, SD

Median, IQR

Min, Max

Total amount used (g)

Mean, SD

Median, IQR

Min, Max

Average amount per use (g)

Mean, SD

Median, IQR

Min, Max

Table 16 Primary outcome, PPPASI

\begin{tabular}{|c|c|c|c|c|c|c|c|c|}
\hline \multirow[t]{3}{*}{ Time } & \multicolumn{6}{|c|}{ Treatment Group } & \multirow{3}{*}{$\begin{array}{l}\text { Total } \\
N\end{array}$} & \multirow{3}{*}{$\begin{array}{l}\text { Unadjusted } \\
\text { Mean } \\
\text { Difference: } \\
(95 \% \mathrm{Cl})\end{array}$} \\
\hline & \multicolumn{3}{|l|}{$\overline{\mathrm{A}}$} & \multicolumn{3}{|l|}{ B } & & \\
\hline & $\bar{N}$ & Mean & SD & $\bar{N}$ & Mean & SD & & \\
\hline \multicolumn{9}{|l|}{ Baseline } \\
\hline \multicolumn{9}{|l|}{ Week 1} \\
\hline \multicolumn{9}{|l|}{ Week 4} \\
\hline \multicolumn{9}{|l|}{ Week 8} \\
\hline Week 12 & & & & & & & & \\
\hline
\end{tabular}

Table 17 Fresh pustule count

\begin{tabular}{|c|c|c|c|c|}
\hline \multirow[t]{3}{*}{ Time } & \multicolumn{2}{|l|}{ Treatment Group } & \multirow{3}{*}{$\begin{array}{l}\text { Total } \\
N\end{array}$} & \multirow{3}{*}{$\begin{array}{l}\text { Unadjusted } \\
\text { Mean } \\
\text { Difference: } \\
(95 \% \mathrm{Cl})\end{array}$} \\
\hline & $\overline{\mathrm{A}}$ & B & & \\
\hline & $\begin{array}{lll}N & \text { Mean } & \text { SD }\end{array}$ & $\bar{N} \quad$ Mean $\quad$ SD & & \\
\hline
\end{tabular}

Week 1

Week 4

Week 8

Week 12

Table 18 Total pustule count

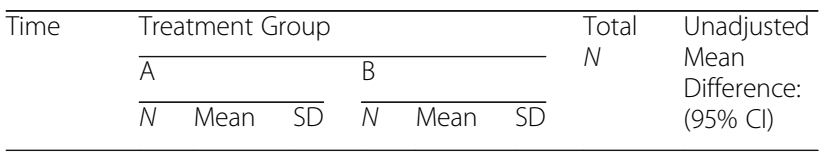

Baseline

Week 1

Week 4

Week 8

Week 12

Table 19 PPP-IGA

Time $N$ Clear Almost clear Mild Moderate Severe

Group A

Baseline

Week 1

Week 4

Week 8

Week 12

Group B

Baseline

Week 1

Week 4

Week 8

Week 12

Table 20 Pustular psoriasis at non-acral sites (body surface area)

\begin{tabular}{|c|c|c|c|c|c|c|}
\hline \multirow[t]{3}{*}{ Time } & \multicolumn{4}{|c|}{ Treatment Group } & \multirow{3}{*}{$\begin{array}{l}\text { Total } \\
N\end{array}$} & \multirow{3}{*}{$\begin{array}{l}\text { Unadjusted } \\
\text { Mean } \\
\text { Difference: } \\
(95 \% \mathrm{Cl})\end{array}$} \\
\hline & \multicolumn{2}{|l|}{$\overline{\mathrm{A}}$} & \multicolumn{2}{|l|}{$B$} & & \\
\hline & $\bar{N} \quad$ Mean & $\overline{S D}$ & $\bar{N} \quad$ Mean & $\overline{\mathrm{SD}}$ & & \\
\hline \multicolumn{7}{|l|}{ Baseline } \\
\hline \multicolumn{7}{|l|}{ Week 1} \\
\hline \multicolumn{7}{|l|}{ Week 4} \\
\hline \multicolumn{7}{|l|}{ Week 8} \\
\hline Week 12 & & & & & & \\
\hline
\end{tabular}


Table 21 Plaque type psoriasis (PASI)

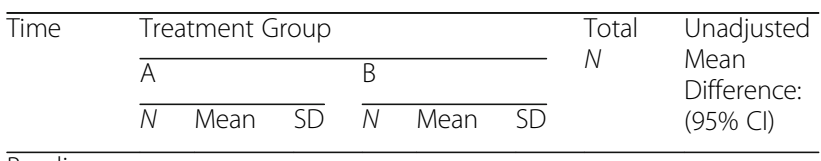

Baseline

Week 4

Week 8

Week 12

Table 22 Participants global assessment

\begin{tabular}{|c|c|c|c|c|c|c|c|}
\hline \multirow[t]{2}{*}{ Time } & \multirow[t]{2}{*}{$N$} & \multicolumn{6}{|c|}{$\overline{P G A}-N(\%)$} \\
\hline & & Clear & Nearly clear & Mild & Moderate & Severe & Very severe \\
\hline \multicolumn{8}{|l|}{$\overline{G r o u p ~ A}$} \\
\hline \multicolumn{8}{|l|}{ Baseline } \\
\hline \multicolumn{8}{|l|}{ Week 1} \\
\hline \multicolumn{8}{|l|}{ Week 4} \\
\hline \multicolumn{8}{|l|}{ Week 8} \\
\hline \multicolumn{8}{|l|}{ Week 12} \\
\hline \multicolumn{8}{|l|}{ Group B } \\
\hline \multicolumn{8}{|l|}{ Baseline } \\
\hline \multicolumn{8}{|l|}{ Week 1} \\
\hline \multicolumn{8}{|l|}{ Week 4} \\
\hline \multicolumn{8}{|l|}{ Week 8} \\
\hline Week 12 & & & & & & & \\
\hline
\end{tabular}

Table 23 Palmoplantar quality of life, DLQI and EQ. 5D-3 L

Index

\begin{tabular}{|c|c|c|c|c|}
\hline \multirow[t]{3}{*}{ Outcome } & \multirow[t]{3}{*}{ Time } & Treatment group & \multirow{3}{*}{$\begin{array}{l}\text { Total } \\
N\end{array}$} & \multirow{3}{*}{$\begin{array}{l}\text { Unadjustec } \\
\text { mean } \\
\text { difference: } \\
(95 \% \mathrm{Cl})\end{array}$} \\
\hline & & $\mathrm{A}$ & & \\
\hline & & $\bar{N}$ Mean SD $\overline{N \text { Mean SD }}$ & & \\
\hline \multirow{2}{*}{$\begin{array}{l}\text { Palmoplantar } \\
\text { QoL }\end{array}$} & Baseline & & & \\
\hline & Week 8 & & & \\
\hline \multirow[t]{2}{*}{ DLQI } & Baseline & & & \\
\hline & Week 8 & & & \\
\hline \multirow{2}{*}{$\begin{array}{l}\text { EQ 5D-3 L } \\
\text { utility }\end{array}$} & Baseline & & & \\
\hline & Week 8 & & & \\
\hline
\end{tabular}

Table 24 Summary of safety events type by treatment group

\begin{tabular}{|c|c|c|c|c|c|c|}
\hline \multirow[t]{2}{*}{$\begin{array}{l}\text { Event } \\
\text { type }\end{array}$} & \multicolumn{3}{|c|}{ Number of Events } & \multicolumn{3}{|c|}{$\begin{array}{l}\text { Number of Participants with } \\
\text { Events }\end{array}$} \\
\hline & $\begin{array}{l}\text { Group A } \\
N=\end{array}$ & $\begin{array}{l}\text { Group B } \\
N=\end{array}$ & $\begin{array}{l}\text { Total } \\
N=\end{array}$ & $\begin{array}{l}\text { Group A } \\
N=\end{array}$ & $\begin{array}{l}\text { Group B } \\
N=\end{array}$ & $\begin{array}{l}\text { Total } \\
N=\end{array}$ \\
\hline \multicolumn{7}{|c|}{ All events } \\
\hline \multicolumn{7}{|l|}{ AE/AR } \\
\hline \multicolumn{7}{|l|}{ UAR } \\
\hline \multicolumn{7}{|c|}{ SAE/SAR } \\
\hline USAR & & & & & & \\
\hline
\end{tabular}

Table $\mathbf{2 5}$ Serious adverse events and reactions by treatment group

\begin{tabular}{|c|c|c|c|c|c|c|}
\hline$d$ & $\begin{array}{l}\text { Serious adverse } \\
\text { reaction }\end{array}$ & Group & $\begin{array}{l}\text { Onset } \\
\text { date }\end{array}$ & $\begin{array}{l}\text { Resolved } \\
\text { date }\end{array}$ & Intensity & Relatedness \\
\hline Id & $\begin{array}{l}\text { Serious adverse } \\
\text { event }\end{array}$ & Group & $\begin{array}{l}\text { Onset } \\
\text { date }\end{array}$ & $\begin{array}{l}\text { Resolved } \\
\text { date }\end{array}$ & ity & 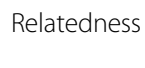 \\
\hline
\end{tabular}

Table $\mathbf{2 6}$ Adverse events and reactions by body system class and treatment group

\begin{tabular}{|c|c|c|c|c|c|c|}
\hline \multirow[t]{2}{*}{ Body system code } & \multicolumn{3}{|c|}{ Number of events } & \multicolumn{3}{|c|}{$\begin{array}{l}\text { Number of participants } \\
\text { with events }\end{array}$} \\
\hline & $\begin{array}{l}\text { Group } \\
\mathrm{A} \\
\mathrm{N}=\end{array}$ & $\begin{array}{l}\text { Group } \\
\text { B } \\
N=\end{array}$ & $\begin{array}{l}\text { Total } \\
N=\end{array}$ & $\begin{array}{l}\text { Group } \\
\text { A } \\
N=\end{array}$ & $\begin{array}{l}\text { Group } \\
\text { B } \\
N=\end{array}$ & $\begin{array}{l}\text { Total } \\
N=\end{array}$ \\
\hline \multicolumn{7}{|l|}{ Respiratory } \\
\hline \multicolumn{7}{|l|}{ Gastro-intestinal } \\
\hline \multicolumn{7}{|l|}{ Genito-urinary } \\
\hline \multicolumn{7}{|l|}{ Musculo-skeletal } \\
\hline \multicolumn{7}{|l|}{ Neurological } \\
\hline \multicolumn{7}{|l|}{ Immunological } \\
\hline \multicolumn{7}{|l|}{ Dermatological } \\
\hline \multicolumn{7}{|l|}{ Allergies } \\
\hline \multicolumn{7}{|l|}{$\begin{array}{l}\text { Eyes, ear, nose, } \\
\text { throat }\end{array}$} \\
\hline \multicolumn{7}{|l|}{ Other } \\
\hline Missing & & & & & & \\
\hline
\end{tabular}

Table $\mathbf{2 7}$ Adverse events at preferred term level by treatment group

\begin{tabular}{llll}
\hline AE term & Group A & Group B & Total \\
& $N$ events & $N$ events & $N$ events
\end{tabular}

Mild events

Moderate events

Severe events

Table 28 Adverse reactions at preferred term level by treatment group

\begin{tabular}{llll}
\hline AE term & Group A & Group B & Total \\
& $N$ events & $N$ events & $N$ events
\end{tabular}

Mild events

Moderate events

Severe events 
Table 29 Summary of harm events by relatedness to infection, event type and treatment group

\begin{tabular}{|c|c|c|c|c|c|c|}
\hline \multirow[t]{3}{*}{ Event Type } & \multirow{2}{*}{$\begin{array}{l}\text { Total } \\
\text { number of } \\
\text { events }\end{array}$} & \multicolumn{2}{|c|}{ Related to an infection } & \multicolumn{3}{|c|}{ Not related to an infection } \\
\hline & & Number of events & Number of participants & & events & Number of participants \\
\hline & $\overline{\mathrm{A}}$ & $\bar{A}$ & $\overline{\mathrm{A}}$ & $\overline{\mathrm{A}}$ & $B$ & $\overline{\mathrm{A}}$ \\
\hline
\end{tabular}

Adverse event

Adverse reaction

Unclassified (non-serious)

Serious adverse event

Serious adverse reaction

Total

Table 30 Numbers prescribed medication for harm events related to an infection by event type and treatment group

\begin{tabular}{|c|c|c|c|}
\hline \multirow[t]{3}{*}{ Event type } & \multirow{2}{*}{$\begin{array}{l}\text { Total } \\
\text { number } \\
\text { of events } \\
\text { related to } \\
\text { infection }\end{array}$} & \multicolumn{2}{|c|}{ Prescribed Medication } \\
\hline & & Number of events & Number of participants \\
\hline & $\bar{A} \quad \mathrm{~B}$ & $\mathrm{~A}$ & $\overline{\mathrm{A}}$ \\
\hline
\end{tabular}

Adverse event

Adverse reaction

Unclassified (non-serious)

Serious adverse event

Serious adverse reaction

Total

Table 31 Details of adverse events which relate to an infection by treatment group

\begin{tabular}{|c|c|c|c|c|c|c|c|c|}
\hline id & $\begin{array}{l}\text { Event } \\
\text { term* }\end{array}$ & $\begin{array}{l}\text { Start } \\
\text { date }\end{array}$ & $\begin{array}{l}\text { On- } \\
\text { going }\end{array}$ & $\begin{array}{l}\text { Stop } \\
\text { date }\end{array}$ & Intensity & $\begin{array}{l}\text { Related } \\
\text { to IMP }\end{array}$ & $\begin{array}{l}\text { Medication } \\
\text { prescribed }\end{array}$ & $\begin{array}{l}\text { Details of } \\
\text { medication } \\
\text { prescribed }\end{array}$ \\
\hline $\begin{array}{l}\text { Group } \\
\text { A }\end{array}$ & & & & & & & & \\
\hline $\begin{array}{l}\text { Group } \\
\text { B }\end{array}$ & & & & & & & & \\
\hline
\end{tabular}

* Indicates study medication was temporarily interrupted

Table 32 Details of adverse reactions which relate to an infection by treatment group

\begin{tabular}{|c|c|c|c|c|c|c|c|c|}
\hline id & $\begin{array}{l}\text { Event } \\
\text { term* }\end{array}$ & $\begin{array}{l}\text { Start } \\
\text { date }\end{array}$ & $\begin{array}{l}\text { On- } \\
\text { going }\end{array}$ & $\begin{array}{l}\text { Stop } \\
\text { date }\end{array}$ & Intensity & $\begin{array}{l}\text { Related } \\
\text { to IMP }\end{array}$ & $\begin{array}{l}\text { Medication } \\
\text { prescribed }\end{array}$ & $\begin{array}{l}\text { Details of } \\
\text { medication } \\
\text { prescribed }\end{array}$ \\
\hline $\begin{array}{l}\text { Group } \\
\text { A }\end{array}$ & & & & & & & & \\
\hline $\begin{array}{l}\text { Group } \\
\text { B }\end{array}$ & & & & & & & & \\
\hline
\end{tabular}

\section{Abbreviations}

AE: adverse event; APRICOT: Anakinra for Pustular Psoriasis: Response in a Controlled Trial; AR: adverse reaction; CACE: complier average causal effect; Cl: confidence interval; CONSORT: Consolidated Standards of Reporting Trials: DLQI: Dermatology Life Quality Index; EME: Efficacy and Mechanism Evaluation Programme; IDMC: independent data monitoring committee; IGA: Investigators Global Assessment; ITT: intention-to-treat; MAR: missing at random; MedDRA: Medical Dictionary for Regulatory Activities; MI: multiple imputation; MNAR: missing-not-at-random; PASI: Psoriasis Area and Severity Index; PGA: Participant's Global Assessment; PPP: palmoplantar pustulosis; PPPASI: Palmoplantar Pustulosis Area and Severity Index; PPPIGA: Palmoplantar Pustulosis Investigators Global Assessment; REML: restricted maximum likelihood; SAE: serious adverse event; SAR: serious adverse reaction; SD: standard deviation; SOBI: Swedish Orphan Biovitrum; SS: safety set; UAR: unexpected adverse reaction; USAR: unexpected serious adverse reaction

\section{Acknowledgements}

The authors wish to acknowledge the NIHR EME programme for funding the study (NIHR EME 13/50/17 APRICOT), SOBI for supplying the study drug and King's Clinical Trials Unit for providing support in the conduct of the trial (Caroline Murphy and Joanna Kelly). The authors would like to thank all the participants and health care professionals for their involvement in the study. We thank the Independent Data Monitoring Committee (Deborah Symmons (Chair), Simon Skene and Michael Ardern-Jones) and the Trial Steering Committee (Edel OToole (Chair), Stephen Kelly, David Britten and Hervé Bachelez) for their advice and contributions to the protocol and statistical analysis plan. We also wish to thank Rosemary Wilson, Angela Pushpa-Rajah and Tao Chen for their early work on the trial. CEMG and RBW are funded by the NIHR Manchester Biomedical Research Centre.

\section{Authors' contributions}

CS is the chief investigator; she conceived the study, obtained grant funding and contributed to the study design. VC obtained grant funding, designed the study, and contributed to the statistical analysis plan. PP contributed to the design and is responsible for acquisition of the data. SC contributed to the design, wrote the statistical analysis plan and wrote the manuscript. JB, $\mathrm{DB}, \mathrm{FC}, \mathrm{CG}, \mathrm{HL}, \mathrm{NR}$, and RW obtained grant funding and contributed to the study design. All authors (SC, CS, PP, JB, DB, FC, CG, HL, NR, RW and VC) contributed to the write-up of this statistical analysis plan for publication, approved the final version to be published and agreed to be accountable for all aspects of the work. All authors read and approved the final manuscript.

\section{Funding}

This investigator-led study is funded by the NIHR EME programme (NIHR EME 13/50/17 APRICOT). The study drug and placebo were supplied by Swedish Orphan Biovitrum (SOBI). SOBI had no role in the design of the study, writing of the protocol or SAP.

\section{Availability of data and materials}

The protocol and statistical analysis plan can be obtained by contacting the corresponding author. The study team will retain the exclusive use of data until publication of major outputs has been completed, when data may be obtained from the chief investigator upon reasonable request. 


\section{Ethics approval and consent to participate}

The APRICOT trial is being conducted in compliance with the principles of the Declaration of Helsinki (1996), the principles of GCP and in accordance with all applicable regulatory requirements. Ethical approval was granted from the London Dulwich Research Ethics Committee (REC), (16/LO/0436). The protocol and study has also been approved by the Health Research Authority (HRA) (Ref: 162093) and the Medicines and Healthcare products Regulatory Agency (MHRA) for Clinical Trial Authorisation (Ref: 11387/0026/ 001). Patients receive an information sheet and provide written informed consent prior to participating in study specific procedures.

\section{Consent for publication}

Not applicable

\section{Competing interests}

CS declares departmental research funding from AbbVie, GSK, Pfizer, Novartis, Regeneron, and Roche. CS is a PI on consortia (BIOMAP https:// www.biomap-imi.eu/ and PSORT http://www.psort.org.uk/) which have a number of industry partners. HJL declares funding from SOBI to support a nurse post in systemic autoinflammatory diseases. FC declares having received funding from Boehringer-Ingelheim and AnaptysBio. DAB declares honoraria for lectures, research or advisory boards from Abbvie, Almirall, Boehringer Ingelheim, Celgene, Janssen, Lilly, Novartis and UCB pharma. CEWG declares AbbVie (AD Board), Almirall (Consultant), BMS (Speaker), Galderma (AD Board), Janssen (Consultant/Speaker), LEO (Speaker), Lilly (AD Board/speaker), Novartis (AD Board/Speaker), Pfizer (AD Board), Samsung Bioepis (Consultant), Sandoz (AD Board), CG Skin (Stockholder), SynDermix (Consultant), UCB Pharma (AD Board), Walgreens Boots Alliance (AD Board/ Speaker) and Celgene (AD Board/Speaker). No competing interests are known for the other authors.

\section{Author details}

IImperial Clinical Trials Unit, Imperial College London, W12 7RH, London, UK. ${ }^{2}$ St. John's Institute of Dermatology, Guy's and St Thomas' NHS Foundation Trust, London, UK. ${ }^{3}$ St. John's Institute of Dermatology, School of Basic \& Medical Biosciences, Faculty of Life Sciences \& Medicine, King's College London, London, UK. ${ }^{4}$ Institute of Infection, Immunity and Inflammation, University of Glasgow, Glasgow G12 8TA, UK. ${ }^{5}$ Centre for Dermatology Research, University of Manchester, NIHR Manchester Biomedical Research Centre, Manchester, UK. ${ }^{6}$ National Amyloidosis Centre, University College London, NW3 2PF, London, UK. Translational and Clinical Research Institute, University of Newcastle, Newcastle upon Tyne NE1 7RU, UK. ${ }^{8}$ Dermatology Centre, Salford Royal NHS Foundation Trust, Manchester NIHR Biomedical Research Centre, The University of Manchester, Manchester, UK. ${ }^{9}$ Department of Medical \& Molecular Genetics, King's College London, London SE1 9RT, UK.

Received: 13 December 2019 Accepted: 21 January 2020

Published online: 10 February 2020

\section{References}

1. Marsland AM, Chalmers RJ, Hollis S, Leonardi-Bee J, Griffiths CE. Interventions for chronic palmoplantar pustulosis. Cochrane Database Syst Rev. 2006;25(1):Cd001433.

2. Li M, Han J, Lu Z, Li H, Zhu K, Cheng R, et al. Prevalent and rare mutations in IL-36RN gene in Chinese patients with generalized pustular psoriasis and psoriasis vulgaris. J Invest Dermatol. 2013;133(11):2637-9.

3. Onoufriadis A, Simpson MA, Pink AE, Di Meglio P, Smith CH, Pullabhatla V, et al. Mutations in IL36RN/IL1F5 are associated with the severe episodic inflammatory skin disease known as generalized pustular psoriasis. Am J Hum Genet. 2011;89(3):432-7.

4. Marrakchi S, Guigue P, Renshaw BR, Puel A, Pei XY, Fraitag S, et al. Interleukin-36-receptor antagonist deficiency and generalized pustular psoriasis. N Engl J Med. 2011;365(7):620-8.

5. Cornelius V, Wilson R, Cro S, Barker J, Burden D, Griffiths CEM, et al. A small population, randomised, placebo-controlled trial to determine the efficacy of anakinra in the treatment of pustular psoriasis: study protocol for the APRICOT trial. Trials. 2018;19(1):465.

6. Cro S, Smith C, Wilson R, Cornelius V. Treatment of pustular psoriasis with anakinra: a statistical analysis plan for stage 1 of an adaptive two-staged randomised placebo-controlled trial. Trials. 2018;19(1):534.
7. Lassus A, Geiger JM. Acitretin and etretinate in the treatment of palmoplantar pustulosis: a double-blind comparative trial. Br J Dermatol. 1988;119(6):755-9.

8. Kahan BC, Morris TP. Reporting and analysis of trials using stratified randomisation in leading medical journals: review and reanalysis. BMJ. 2012; 345:e5840.

9. Kahan BC, Morris TP. Analysis of multicentre trials with continuous outcomes: When and how should we account for centre effects? Stat Med. 2013;32(7):1136-49.

10. Senn SJ. Covariate imbalance and random allocation in clinical trials. Stat Med. 1989:8(4):467-75.

11. Moher D, Schulz KF, Altman DG. The CONSORT statement: revised recommendations for improving the quality of reports of parallel-group randomised trials. Lancet. 2001;357(9263):1191-4.

12. European Medicines Agency. Guideline on adjustment for baseline covariates in clinical trials. London: 2015. EMA/CHMP/295050/2013.

13. Pickering RM, Weatherall $M$. The analysis of continuous outcomes in multicentre trials with small centre sizes. Stat Med. 2007;26(30):5445-56.

14. Carpenter J, Kenward MG. Missing data in randomised controlled trials - a practical guide. Birmingham: National Institute for Health Research; 2007.

15. White IR, Royston P, Wood AM. Multiple imputation using chained equations: Issues and guidance for practice. Stat Med. 2011;30(4):377-99.

16. Hardt J, Herke M, Leonhart R. Auxiliary variables in multiple imputation in regression with missing $\mathrm{X}$ : a warning against including too many in small sample research. BMC Med Res Methodol. 2012;12(1):184.

17. Rabe-hesketh S, Skrondal A. Multilevel and longitudinal modeling using stata. Third ed. College Station: Stata Press; 2012.

18. Zink RC, Wolfinger RD, Mann G. Summarizing the incidence of adverse events using volcano plots and time intervals. Clin Trials. 2013;10(3):398-406.

19. White IR, Thompson SG. Adjusting for partially missing baseline measurements in randomized trials. Stat Med. 2005;24(7):993-1007.

20. Sullivan $T R$, White $I R$, Salter $A B$, Ryan $P$, Lee KJ. Should multiple imputation be the method of choice for handling missing data in randomized trials? Stat Methods Med Res. 2018;27(9):2610-26.

21. Gamble C, Krishan A, Stocken D, lewis $\mathrm{S}$, Juszczak e, Doré C, et al. Guidelines for the content of statistical analysis plans in clinical trials. JAMA. 2017; 318(23):2337-43.

\section{Publisher's Note}

Springer Nature remains neutral with regard to jurisdictional claims in published maps and institutional affiliations.

Ready to submit your research? Choose BMC and benefit from:

- fast, convenient online submission

- thorough peer review by experienced researchers in your field

- rapid publication on acceptance

- support for research data, including large and complex data types

- gold Open Access which fosters wider collaboration and increased citations

- maximum visibility for your research: over $100 \mathrm{M}$ website views per year

At BMC, research is always in progress.

Learn more biomedcentral.com/submissions 